\title{
neuroRAD_-Idea and Realization of a New Concept
}

\section{O. Jansen}

Published online: 17 November 2011

(C) Springer-Verlag 2011

In the first week of October 2011 the 46th annual meeting of the German Society of Neuroradiology (Deutsche Gesellschaft für Neuroradiologie, DGNR) took place again in Cologne, named neuroRAD 2011. After 2009 and 2010 this new concept of the annual German meeting inspired again nearly 1,200 participants to attend with a successful mixture of teaching, science and industry.

The executive board of the DGNR decided to change the concept and location of the annual society meeting 4 years ago and founded neuroRAD, the new annual meeting platform, together with the congress organizer. The reason for this was the continuous decrease in congress participants over the years and comments from the industry that this kind of annual scientific meeting with changing locations and a rather small number of participants (300-400) will become more and more difficult to be sponsored.

The board decided to change the meeting concept and chose Cologne for the next years as the fixed congress site. Over the years and with the development of magnetic resonance imaging (MRI) and computed tomography (CT) neuroradiology has become a specialty of common interest for radiologists, neurologists and other neuroscientists. Having this in mind the board decided to implement a major tea- ching platform into the congress. Parallel scientific sessions, poster sessions, industry-sponsored symposia and special teaching sessions for technicians (this year more than 300 participants) offer a broad choice of education not only for neuroradiologists. However, with nearly 190 scientific contributions there is also a huge platform to communicate and discuss new developments in diagnostic and therapeutic neuroradiology.

neuroRAD 2011 also had a large and positive feedback from industry and succeeded to implement several sponsored sessions and a large industrial forum.

With the third year in line with more than 1,000 participants neuroRAD has become established as the largest neuroradiological congress in Europe. The board of the DGNR will hold on to this successful concept of its annual society meeting as an open and exciting platform for all who are interested in clinical and scientific neuroradiology.

Prof. Dr. Olav Jansen

President of the German Society of Neuroradiology

Congress President of neuroRAD 2011
O. Jansen $(\bowtie)$

Kiel, Germany

e-mail: o.jansen@neurorad.uni-kiel.de 